\title{
Empirical correspondence between trophic transfer efficiency in freshwater food webs and the slope of their size spectra
}

\author{
Thomas Mehner (iD,${ }^{1,7}$ Betty Lischke, ${ }^{1}$ Kristin Scharnweber, ${ }^{1,2}$ Katrin Attermeyer, ${ }^{1,2}$ Soren Brothers, ${ }^{1,3}$ \\ Ursula Gaedke, ${ }^{4}$ Sabine Hilt, ${ }^{1}$ and Sandra Brucet ${ }^{5,6}$ \\ ${ }^{1}$ Leibniz-Institute of Freshwater Ecology and Inland Fisheries, Müggelseedamm 301 \& 310, 12587 Berlin, Germany \\ ${ }^{2}$ Department of Ecology and Genetics, Limnology, Uppsala University, Norbyvägen 18D, 75236 Uppsala, Sweden \\ ${ }^{3}$ Department of Watershed Sciences and Ecology Center, Utah State University, 5210 Old Main Hill, Logan, Utah $84322-5200$ USA \\ ${ }^{4}$ Institute for Biochemistry and Biology, University of Potsdam, Am Neuen Palais 10, 14469 Potsdam, Germany \\ ${ }^{5}$ Aquatic Ecology Group, University of Vic - Central University of Catalonia, cl de la Laura, 1308500 Vic, Barcelona, Catalonia, Spain \\ ${ }^{6}$ Catalan Institution for Research and Advanced Studies ICREA, Passeig Lluís Companys, 23, 08010 Barcelona, Catalonia, Spain
}

\begin{abstract}
The density of organisms declines with size, because larger organisms need more energy than smaller ones and energetic losses occur when larger organisms feed on smaller ones. A potential expression of density-size distributions are Normalized Biomass Size Spectra (NBSS), which plot the logarithm of biomass independent of taxonomy within bins of logarithmic organismal size, divided by the bin width. Theoretically, the NBSS slope of multi-trophic communities is exactly -1.0 if the trophic transfer efficiency (TTE, ratio of production rates between adjacent trophic levels) is $10 \%$ and the predator-prey mass ratio (PPMR) is fixed at $10^{4}$. Here we provide evidence from four multi-trophic lake food webs that empirically estimated TTEs correspond to empirically estimated slopes of the respective community NBSS. Each of the NBSS considered pelagic and benthic organisms spanning size ranges from bacteria to fish, all sampled over three seasons in $1 \mathrm{yr}$. The four NBSS slopes were significantly steeper than -1.0 (range -1.14 to -1.19 , with $95 \%$ CIs excluding -1 ). The corresponding average TTEs were substantially lower than $10 \%$ in each of the four food webs (range $1.0 \%$ to $3.6 \%$, mean $1.85 \%)$. The overall slope merging all biomass-size data pairs from the four systems $(-1.17)$ was almost identical to the slope predicted from the arithmetic mean TTE of the four food webs $(-1.18)$ assuming a constant PPMR of $10^{4}$. Accordingly, our empirical data confirm the theoretically predicted quantitative relationship between TTE and the slope of the biomass-size distribution. Furthermore, we show that benthic and pelagic organisms can be merged into a community NBSS, but future studies have yet to explore potential differences in habitat-specific TTEs and PPMRs. We suggest that community NBSS may provide valuable information on the structure of food webs and their energetic pathways, and can result in improved accuracy of TTE-estimates.
\end{abstract}

Key words: energetic equivalence rule; metabolic theory of ecology; multi-trophic communities; normalized biomass size spectra; pelagic and benthic lake habitats; size of organisms.

\section{INTRODUCTION}

The relationship between body size, density, and energy use of organisms is a central research topic in ecology (White et al. 2007). The often observed exponential decline of densities $(D)$ of populations sharing a common resource with average body size $(M)$ at $D \sim M^{-0.75}$ (Damuth 1981, Nee et al. 1991) is caused by energy availability, which directly modifies the density of organisms, mediated by the size-dependent metabolic rates of the individuals (Metabolic Theory of Ecology, MTE, Brown et al. 2004). However, the exponent of empirical density-size distributions of all organisms independent of taxonomy at a certain location is often substantially smaller than -0.75 (Gaedke 1992, Cyr 1997, Marquet 2000). In these communities forming multi-trophic food webs in which larger organisms feed on smaller ones, energy is lost by trophic transfer between trophic levels. Accordingly, the total energy available to larger organisms is lower than that for smaller organisms, resulting in more negative exponents of density-size distributions than predicted

Manuscript received 30 August 2017; revised 9 January 2018; accepted 5 April 2018. Corresponding Editor: Shelley E. Arnott.

${ }^{7}$ E-mail: mehner@igb-berlin.de (as above) for populations where all individuals use the same resource.

The energy transfer within multi-trophic food webs is quantified by the trophic transfer efficiency (TTE), which is the proportion of resource (prey) production converted into consumer (predator) production. It has traditionally been assumed that the TTE between adjacent trophic levels is roughly $10 \%$ (Lindeman 1942). The size relationships between predator and prey are quantified by the predatorprey mass ratio (PPMR), which is assumed to be around $10^{4}$ in aquatic open-water habitats (Trebilco et al. 2013). Therefore, the exponent of the density-size distribution is theoretically predicted to decline from -0.75 , when all organisms feed on the same resource, to exactly -1.0 in multi-trophic food webs with TTE $=10 \%$ and PPMR $=10^{4}$ (see Theoretical background below). This TTE-correction of the densitysize distributions combines two independently developed relationships, the decline of density with size (summarized by Brown et al. 2004), and the concept of trophic levels connected by predator-prey interactions, in which only a part of the total energy is transferred from one level to the next (summarized by Trebilco et al. 2013). Both concepts are based on independent empirical observations, yet they share the common physiological basis that the density of 
organisms is dictated by the size-dependent balance between available resources and metabolic efficiency.

The trophic level concept of predators being less abundant and larger than their prey is supported by studies of the open-water areas of aquatic ecosystems. Accordingly, exponents $<-0.75$ of density-size distributions were often found in multi-trophic food webs in these habitats (Brown and Gillooly 2003, Reuman et al. 2008). Furthermore, an earlier study in Lake Constance (Germany/Switzerland/Austria) has shown corresponding changes in PPMR, TTE, and exponents of density-size distributions across several samplings within a single year (Gaedke et al. 1996). However, here we intended to expand the empirical confirmation of the TTE-correction by demonstrating the quantitative correspondence between the exponents of density-size distributions for multi-trophic food webs and their transfer efficiencies across multiple ecosystems. Hence, we adopted a community energy perspective and focused on the interplay between TTE and the NBSS slope by assuming a fixed PPMR, although mechanistic explanations may also be provided by process-based models which considered individual predator-prey interactions resulting in similar energetic constraints (Kerr and Dickie 2001, Andersen and Beyer 2006, Law et al. 2009, Hartvig et al. 2011, Rossberg 2012).

Community size distributions composed of several trophic levels are often expressed as abundance or biomass size spectra, especially in aquatic systems (Sprules and Barth 2016). Size spectra are linear regressions between the logarithm of either abundance or biomass vs. the logarithm of body mass, as obtained by logarithmic binning. The slopes of these linear log-log regressions are related to the exponent of the density-size distributions. If the size spectra are normalized by the width of the respective size class, the slope of the normalized biomass size spectrum (NBSS) can be used to directly estimate the exponent of the biomass-size distribution (White et al. 2008). Most of the aquatic community size spectra published so far for lakes only included phytoplankton, zooplankton, and occasionally fish (Sprules 2008, Yurista et al. 2014). In rare cases, protozoa and bacteria have also been included (Gaedke 1992, Gaedke et al. 1996). Surprisingly few studies have incorporated the benthic habitats of lakes, although size spectra are available for marine benthic communities (Blanchard et al. 2009, Rogers et al. 2014). Benthic and pelagic (water column) food chains may be closely linked (Vadeboncoeur et al. 2002, Brothers et al. 2016), but the integration of benthic and pelagic size spectra into a single community biomass spectrum has never been conducted in freshwater ecosystems.

In this study, we aimed to demonstrate that the TTE and the slope of a community NBSS are quantitatively related, thus empirically confirming the hypothesized TTE-correction of the biomass-size distributions. We measured the biomass and size of benthic and pelagic organisms ranging from bacteria to fish in four separate lake food webs, and calculated biomass spectrum slopes. Furthermore, we measured the TTE in each of the four food webs by comparing primary and bacterial production with consumer secondary production, and predicted the respective slopes of biomass spectra according to the TTE-correction. Finally, by integrating benthic and pelagic food webs into the same NBSS, we explored differences in biomasses of producer and consumer groups between these habitats through examining the systematic residual variations of these groups from the slopes of the community size distributions.

\section{Methods}

\section{Theoretical background}

Following Reuman et al. (2008), the size distribution of individuals sharing a common resource is a power law of individual size ( $M$, mass) in the form of

$$
f(M) \propto M^{-1.75}
$$

In communities where organisms from the lowest trophic level are the only ones to exploit the basal resource, and larger organisms from higher trophic levels consume smaller organisms from lower trophic levels, a decrease of abundance with increasing size is also influenced by the energy transfer efficiency between trophic levels and the size relationships between predator and prey. Accordingly, the community abundance distribution can be estimated as

$$
f(M) \propto M^{\frac{\log (\mathrm{TTE})}{\log (\mathrm{PPMR})}-1.75}
$$

With TTE $=$ trophic transfer efficiency between trophic levels and PPMR = average predator-prey body mass ratio, assuming neither TTE nor PPMR vary systematically with $M$. This assumption is appropriate for the predator-prey pairs typically dominating open-water habitats of aquatic ecosystems. Because biomass $(B)$ is the product of numbers $(N)$ and $M$, the community biomass distribution is

$$
f(B) \propto M^{\frac{\log (\mathrm{TTE})}{\log (\mathrm{PPMR})}-0.75}=M^{\alpha}
$$

with $\alpha$ being the exponent of the power law of $B$ with $M$. By considering a PPMR of $10^{4}(10,000)$ and a TTE of $10 \%$ (10 ${ }^{-1}$; Pauly and Christensen 1995, Trebilco et al. 2013),

$$
\alpha=\frac{\log (0.1)}{\log (10,000)}-0.75=-1
$$

The slope $\beta$ of the linear regression between log biomass and log body size in logarithmic bins (biomass size spectrum, BSS) is zero. Therefore, the exponent $\alpha$ can be indirectly estimated as

$$
\alpha=\beta-1
$$

However, normalizing the BSS by the width of the respective size class (normalized biomass size spectrum, NBSS) reduces the slope by 1 , and hence the NBSS slope can be used to directly estimate $\alpha$ (White et al. 2008). For communities with TTE $=10 \%$ and PPMR $=10^{4}, \alpha=-1$. For communities with TTE $<10 \%$ and PPMR $=10^{4}$, the TTE-correction predicts $\alpha<-1$ and $\beta<0$. These predictions are equivalent to a TTE-corrected Energetic Equivalence Rule (ERR), as proposed earlier (Damuth 1981, Nee et al. 1991). The EER emerges from the size-dependency of metabolic rates of organisms (exponent $=0.75)$ combined with an exponential 
decline of population densities sharing a common resource with average body size (exponent $=-0.75$ ), resulting in a power law stating that energy use scales with organismal size with an exponent of zero. The EER likewise predicts that the energy-use scaling in multi-trophic food webs would decline from zero to -0.25 through TTE and PPMR corrections (Reuman et al. 2008, Trebilco et al. 2013).

\section{Empirical background}

Data were obtained from whole-lake experiments conducted in two lakes, Schulzensee and Kleiner Gollinsee (hereafter referred to as Gollinsee), both located in northeastern Germany. Both lakes were eutrophic (32-40 $\mu \mathrm{g}$ total phosphorus/L), shallow (mean depth about $2 \mathrm{~m}$ ) and small (3-4 ha surface area), but only Schulzensee contained submerged macrophytes (Brothers et al. 2013). We conducted whole-lake experiments as part of an unrelated project starting in October 2010 (Scharnweber et al. 2014, Mehner et al. 2016), for which both lakes were divided in an east-west direction by a plastic curtain, producing fully isolated, equally sized halves. These long-term lake divisions created lake halves with some differences in the dominant organism groups. Consequently, we consider the north and south halves of both lakes as independent replicates for subsequent calculations (see Results for confirmation of this assumption).

\section{Sampling}

Sampling was conducted in spring (April), summer (June), and autumn (October) 2011. Organism biomasses were converted to $\mathrm{g}$ carbon $(\mathrm{C})$ per $\mathrm{m}^{2}$ and individual mass was converted to g C (see Appendix S1 for details of conversions between units). Bacteria, phytoplankton, and zooplankton measurements from pelagic and littoral locations were arithmetically averaged as we assumed the lake waters to be horizontally well mixed, as indicated by similar planktonic community compositions and biomasses at both locations. We refer to these samples as pelagic, in contrast to samples from the benthic habitats (sediment bacteria and benthic macroinvertebrates). Sampling details have been described elsewhere (Brothers et al. 2013, Mehner et al. 2016), and the procedures are summarized in Appendix S1. Biomasses and sizes were measured for pelagic and benthic bacteria, 65 phytoplankton morphotypes, 39 ciliate morphotypes, 37 rotifer morphotypes, 47 crustacean morphotypes, 15 macrozoobenthos morphotypes, and individual sizes of 5 fish species (Appendix S1: Table S1).

\section{Biomass size spectra}

To calculate size spectra, we allocated the biomass of all organisms (from bacteria to fish) into logarithmically-binned body size classes (biomass size spectrum, BSS, expressed in C units). Therefore, the average $\mathrm{C}$ mass per organismal morphotype (bacteria, phytoplankton, ciliates, rotifers, crustaceans, macrozoobenthos) or individual mass (fish) was assigned to one of $53 \log _{2}$ size classes $\left(1\right.$ st class $>2^{-45.5} \sim 20 \mathrm{fg}$ C/ind to $\leq 2^{-44.5} \sim 40 \mathrm{fg} \mathrm{C/ind} ; . . .53$ rd class $>2^{6.5} \sim 90 \mathrm{~g}$ C/ind to $2^{7.5} \sim 180$ g C/ind; Appendix S1: Table S1, Fig. S1), and the respective biomasses of morphotypes were summed per size class. Morphotypes partly overlapped in size such that occasionally different groups of organisms were pooled within a single $\log _{2}$ size class. To account for size variability within bacterial groups resulting, for instance, from cell division, the measured bacterial biomass was distributed over three $\log _{2}$ size classes by assigning only $50 \%$ of the biomass to the average size class of the respective bacterial group and allocating $25 \%$ each to the neighboring lower and higher size classes. This biomass distribution roughly corresponded to the size distribution obtained from single- cell measurements during some of the sampling days (B. Lischke, unpublished results).

The biomass per $\log _{2}$ size class was divided by the width of the respective size class to normalize the size spectrum (normalized biomass size spectrum, NBSS, White et al. 2008). The normalized biomass is numerically close to the abundance per size class. The slope of the NBSS was obtained from linear least-squares regressions between the logarithm of the normalized summed biomass per $\log _{2}$ size class and the midpoint of each $\log _{2}$ size class. The NBSS slope is identical to the exponent of the TTE-corrected biomass-size distribution ( $\alpha$; White et al. 2008), and hence at $\mathrm{TTE}=10 \%$ and PPMR $=10^{4}$, the theoretical NBSS slope would be -1 . We calculated three size spectra per lake half (one from each sampling season), resulting in 12 spectra in total, incorporating all organisms from bacteria to macrozoobenthos. Fish data were available only in autumn, and hence we created one additional size spectrum per lake half, which included fish.

Applying linear regression models to size data binned in linear or logarithmic size classes results in a loss of the biomass variability over the size gradient within a binned size class, which may lead to inaccurate estimates of the NBSS slope. This can be circumvented using continuous size distributions (White et al. 2008). However, exact sizing of all individual organisms from bacteria to fish was impossible because of the numerous morphotypes included in each trophic group. We instead had to rely on the average size and biomasses of morphotypes in many groups of organisms, and there was thus no alternative except to calculate the NBSS slope by linear regression.

\section{Trophic transfer efficiency}

In a recent study, we assessed the biomass and production of autotrophs, bacteria, and consumers in the pelagic and benthic habitats of the northern halves of Gollinsee and Schulzensee and aggregated these data to seasonally averaged quantitative food webs (Lischke et al. 2017). Subsequently, trophic transfer efficiencies (TTEs) were calculated as the ratio of consumer production to resource production, hence indicating the efficiency of resource utilization by the consumers. To obtain similar estimates for the southern halves of both lakes, quantitative food webs and TTE calculations were repeated following the same approach. In short, we calculated the gross and net primary production (GPP, NPP) of submerged macrophytes from summer biomass measurements (Best 1982). The GPP of phytoplankton was calculated every two to 4 weeks from the measured quantum yield of photosystem II, specific absorption cross section, the efficiency of carbon assimilation, and the intensity of photosynthetically active radiation at $10 \mathrm{~cm}$ depth intervals 
(Brothers et al. 2013). For periphyton (epiphyton and epipelon), submerged plastic strips were exposed in the pelagic zone at $1.2 \mathrm{~m}$ below the surface to measure monthly periphyton biomass accumulation and production rates, which were then converted to epiphyton and epipelon production based on measurements of underwater plant surface area and sediment surface area estimates, respectively (Brothers et al. 2013). Algal NPP rates were estimated from measured GPP rates (details provided in Lischke et al. 2017). Bacterial production rates were measured via the incorporation of $\mathrm{L}^{14} \mathrm{C}$ leucine into the protein fraction (following Simon and Azam 1989 for water, and Buesing and Gessner 2003 for sediments). Rotifer production rates were estimated using a linear regression model accounting for total biomass and temperature (Shuter and Ing 1997). Production estimates for crustaceans were based on the individual size and biomass of each species using two sets of specific parameters for water temperatures above and below $10^{\circ} \mathrm{C}$ (Stockwell and Johannson 1997). The annual macrozoobenthos production was estimated using the allometry-based approach of Plante and Downing (1989), which includes macrozoobenthos biomass, individual mass, and ambient temperature. For each of the four lake halves, we calculated the TTE as the ratio between the sum of macrozoobenthos, rotifer, and crustacean production, divided by the sum of bacterial (sediment and pelagic) and autotrophic (phytoplankton, periphyton, epipelon, and macrophyte) production. These four groups of primary producers contributed to the diet of the consumers in both lakes (Syväranta et al. 2016).

\section{Analyses}

To evaluate whether the empirically determined NBSS slope deviated from -1 , we checked whether the $95 \%$ confidence intervals (CIs) of the slopes excluded -1 . For a more detailed analysis, we calculated a linear mixed effect model (LMM). The model included lake, sampling season, lake division (north vs. south), the interaction of lake with size class, and the interaction of lake division with size class all as fixed effects, and further accounted for the serial autocorrelation within lake halves by including a random effect as:

$$
\begin{gathered}
\log _{2}(\text { normalized biomass }) \sim \log _{2} \text { size class }+ \text { lake } \\
+ \text { season }+ \text { lake division }+ \text { lake }: \log _{2} \text { size class } \\
+ \text { lake division }: \log _{2} \text { size class }+(1 \mid \text { lake half }) .
\end{gathered}
$$

This LMM was defined to test for differences in the slopes of the NBSS between the four lake halves, excluding fish. Hence, we considered only the full model and did not perform model selection. A non-significant lake-division effect would justify our approach to consider both lake halves as replicates. A significant lake-by-size-class interaction would indicate different NBSS slopes between the lakes and a significant lake-division-by-size-class interaction would indicate different NBSS slopes between northern and southern lake halves.

To evaluate whether the biomasses of certain producer or consumer groups deviated systematically from the slope of the NBSS, we merged all available biomass-size data pairs $(n=1,122)$ from all lake halves and calculated an average slope for all measurements by linear least-squares regression. We then calculated the arithmetic average residuals from the regression for each organismal group to assess group-specific deviations from the community-wide biomass-size relationship. In cases where more than one organismal group contributed to the biomass of a single size class (13 out of 38 size classes excluding fish), the biomass of the size class was assigned to whichever organismal group dominated by biomass.

The empirically estimated NBSS slopes in the four lake halves were correlated with the theoretical NBSS slopes as predicted from the lake-half specific TTE (Eq. 3, assuming a constant PPMR $=10^{4}$ ) by Spearman's rank correlation coefficient. The arithmetic average of empirical TTEs from the four lake halves was compared with the slope of the aggregated NBSS of the four lake halves.

Statistical analyses were performed in $\mathrm{R}$ version 3.2.4 ( $\mathrm{R}$ Core Team 2016) using the packages lme4, lmerTest and lsmeans for the linear mixed effect model analyses.

\section{RESULTS}

The community-wide NBSS from bacteria to fish covered $53 \log _{2}$ size classes. The NBSS slopes from bacteria to macrozoobenthos of each lake half per season ranged from -1.21 to -1.13 (Fig. 1). The $95 \%$ confidence intervals of all slopes overlapped, and did not include -1 (Fig. 1). When fish size-biomass data were included, the slopes became slightly less steep than those covering only bacteria to macrozoobenthos, ranging from -1.15 to -1.08 , with their CIs likewise excluding -1 (Appendix S1: Fig. S2). However, the CIs overlapped with those of the NBSS without fish.

Merging all biomass-size measurements from bacteria to macrozoobenthos across the three sampled seasons, but separately for all four lake halves, provided an average slope of -1.14 [95\% CI : $-1.2,-1.09]$ for Gollinsee (north), -1.19 $[-1.24,-1.13]$ for Gollinsee (south), -1.17 [-1.22, -1.12] for Schulzensee (north) and likewise -1.17 [-1.22, -1.11$]$ for Schulzensee (south). These slopes did not differ between the four lake halves (Table 1, linear mixed model; non-significant interactions lake-by-size class and lake division-bysize class, Appendix S1: Table S2).

The overall slope of the NBSS, merging all data from bacteria to macrozoobenthos from both northern and southern halves of both lakes in each season, was -1.17 [ -1.19 , -1.14] (Fig. 2). The average group-wise residuals from this regression line were positive for sediment bacteria, ciliates, and macrozoobenthos, whereas pelagic bacteria, rotifers, and crustaceans had negative residuals (Table 2).

Whole-lake TTEs, comparing the sum of rotifer, crustacean, and macrozoobenthos production (primary consumers) against the sum of pelagic and benthic autotrophic and bacterial production, were $3.5 \%$ and $1.5 \%$ in northern and southern halves of Schulzensee, respectively, and $1.4 \%$ and $1.0 \%$ in northern and southern halves of Gollinsee, respectively (Appendix S1: Fig. S3). By assuming a PPMR of $10^{4}$, these TTEs result in NBSS slopes ranging between -1.25 (Gollinsee, south), -1.21 (Gollinsee, north and Schulzensee, south), and -1.11 (Schulzensee, north).

There was no correlation between the empirically determined slopes in the four lake halves and the slopes predicted 

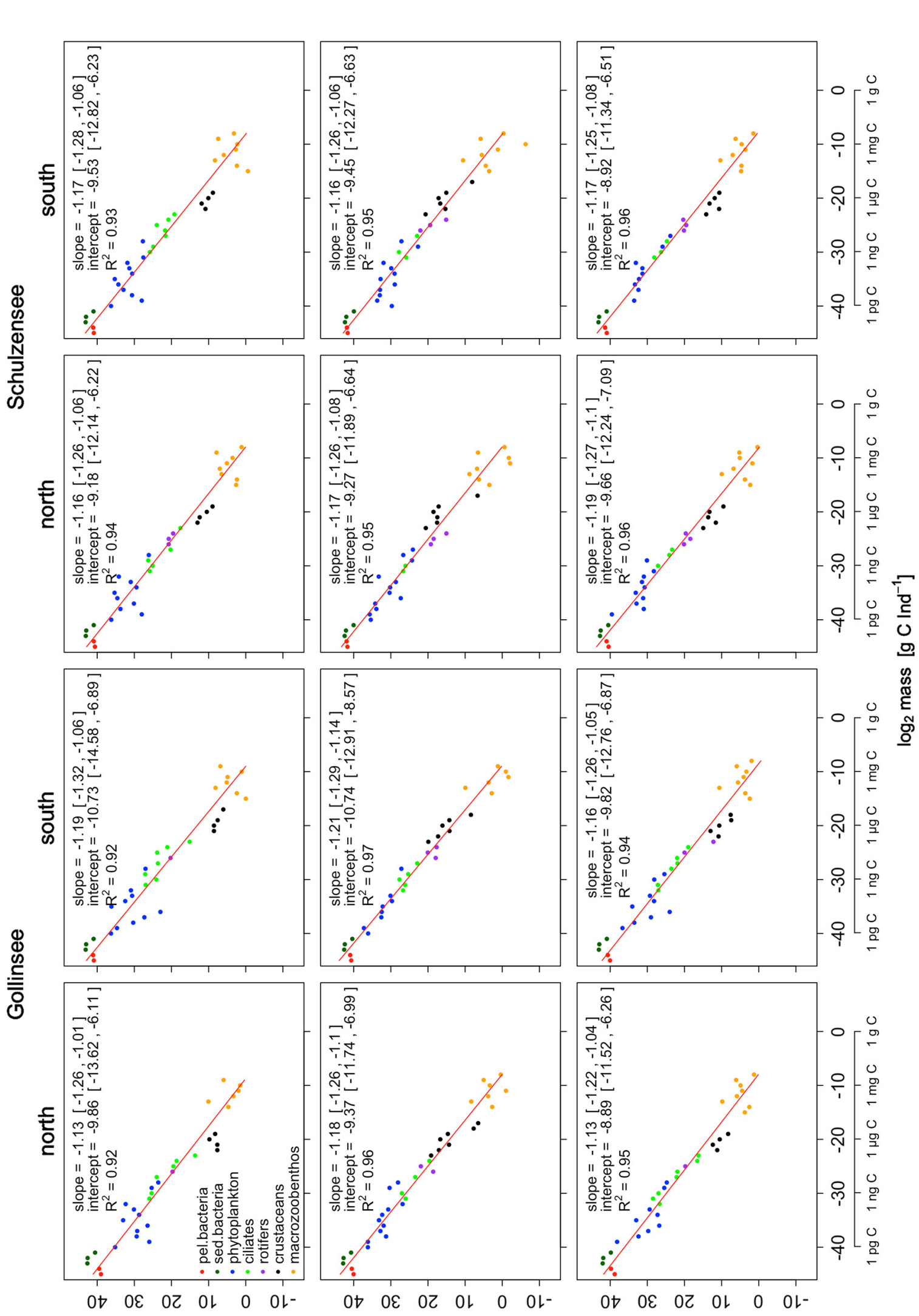

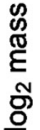

爱宅

运责

范言总

究.

可诺

क ज

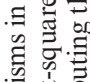
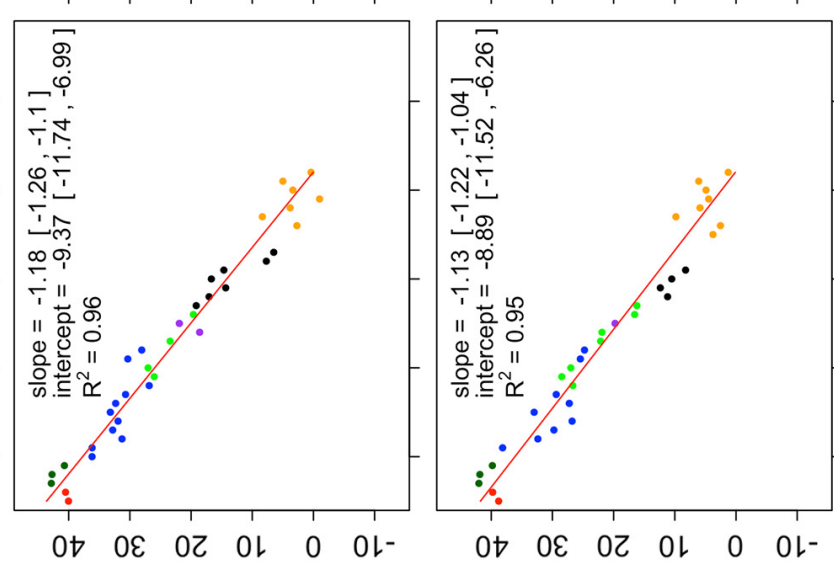

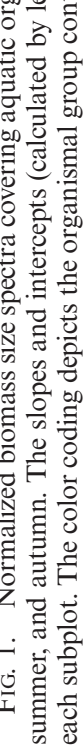

Gu!̣ds

[z-u] ssemo!q pəz!|eusou Jəuums

uunłne

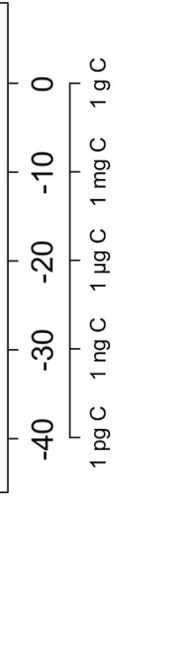


TABLE 1. Results of a linear mixed effect model to test for differences in biomasses of organisms in the four lake halves.

\begin{tabular}{lcccc}
\hline \hline Factor & df & $F$-value & $P$-value & Tendency \\
\hline Size class & 1 & 7,081 & $<0.001$ & GS $<$ SS \\
Lake & 1 & 0.4 & 0.51 & Spring $<$ autumn $<$ summer \\
Season & 2 & 1.3 & 0.28 & Southern $<$ northern \\
Lake division & 1 & 0.4 & 0.55 & 0.93 \\
Lake : size class & 1 & 0.007 & 0.50 & \\
Lake division : size class & 1 & 0.5 & \\
\hline
\end{tabular}

Notes: All data pairs of $\log _{2}$ normalized biomass and $\log _{2}$ size classes from bacteria to macrozoobenthos of northern and southern halves in both lakes (GS, Gollinsee; SS, Schulzensee) and three seasons (spring, summer, autumn) were included. The degrees of freedom (df), the $F$-value and the $P$-value of the ANOVA are shown. For non-significant effects, the tendency is shown. Model: $\log _{2}($ normalized biomass) $\sim \log _{2}$ size class + lake + season + lake division + lake $: \log _{2}$ size class + lake division $: \log _{2}$ size class + (1llake half) (see Methods for model description).

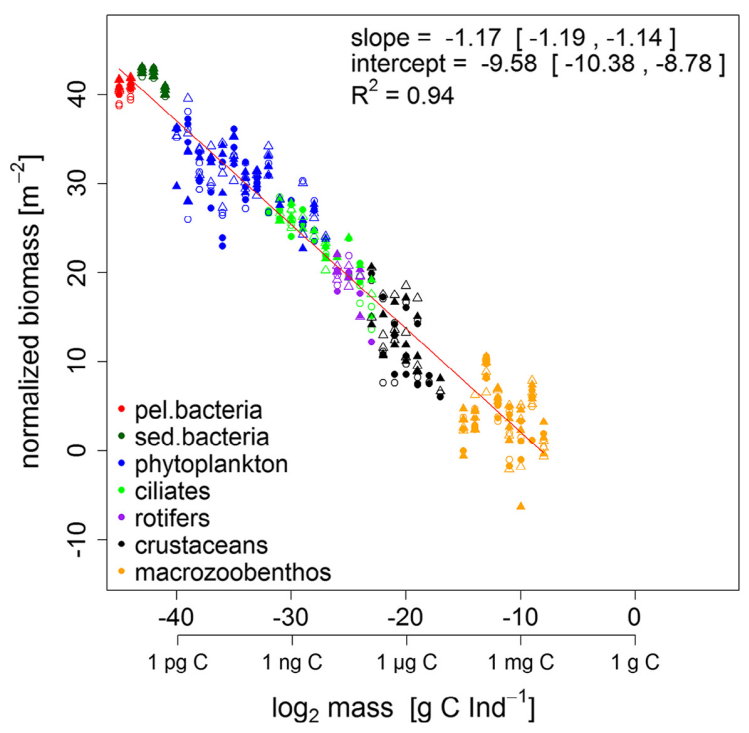

FIG. 2. Normalized biomass size spectrum including biomasssize data from bacteria to macrozoobenthos merged from northern (open symbols) and southern (filled symbols) halves of Gollinsee (circles) and Schulzensee (triangles) in spring, summer, and autumn 2011 (season not coded). Group-wise residuals were calculated against the overall linear regression (red line). The slope and intercept as calculated by least-squares linear regression, with the respective $95 \%$ confidence intervals, and $R^{2}$ of the linear regression (red line) are shown. The color coding depicts the organismal group contributing the largest biomass to the respective $\log _{2}$ size class (pel. bacteria, pelagic bacteria; sed. bacteria, sediment bacteria).

TABLE 2. Arithmetic mean group-wise residuals $\left(\log _{2}\right.$ normalized biomass) from the linear regression including all data pairs of $\log _{2}$ normalized biomass and $\log _{2}$ size class from bacteria to macrozoobenthos for all four lake halves and three seasons combined.

\begin{tabular}{lcc}
\hline \hline Organismal group & Mean residuals & Number of data points \\
\hline Pelagic bacteria & -1.65 & 24 \\
Sediment bacteria & 2.57 & 36 \\
Phytoplankton & 0.05 & 121 \\
Ciliates & 0.78 & 58 \\
Rotifers & -0.67 & 25 \\
Crustaceans & -1.81 & 60 \\
Macrozoobenthos & 0.24 & 90 \\
\hline
\end{tabular}

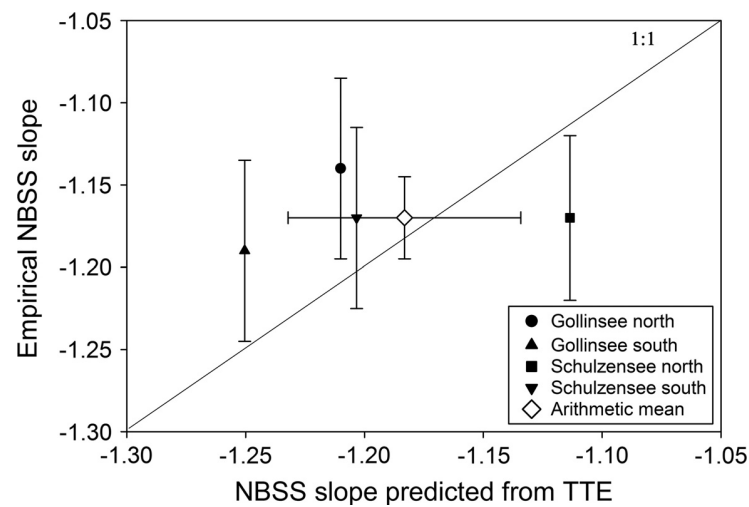

FIG. 3. Comparison of slopes of normalized biomass size spectra (NBSS) as predicted from the empirically estimated trophic transfer efficiency (TTE), and the empirically determined NBSS slopes $( \pm 95 \%$ CI $)$ in the northern and southern halves of Lakes Gollinsee and Schulzensee. The open symbol reflects the mean slope $( \pm 95 \% \mathrm{CI})$ as predicted from the arithmetic mean TTE from all four lake halves, and the slope and $95 \%$ CI from the NBSS merged from all available biomass-size data pairs from all four lake halves. The line of unity (1:1) is given for comparison. A constant predator : prey mass ratio (PPMR) of $10^{4}$ is applied in all cases.

from the empirically estimated TTEs (Spearman's rho $=0.22$, $P=0.68$, Fig. 3). However, the overall slope merging all biomass-size data pairs from the four lake halves $(-1.17)$ was almost identical to the slope $(-1.18)$ predicted from the arithmetic mean TTE (1.85\%) from the four lake halves (Fig. 3).

\section{DisCUSSION}

Our analyses indicated that the slopes of the community NBSS from bacteria to macrozoobenthos in both lakes and in their northern and southern halves were always significantly more negative than -1 , suggesting that the TTE in these four food webs was substantially lower than $10 \%$. Empirical estimates in the lakes confirmed that the TTE between producers and primary consumers ranged from $1 \%$ to $3.5 \%$. The differences in TTE between the four lake halves did not correlate with the NBSS slopes in the respective food webs. However, if the average TTE from all four food webs was used to predict the slope of the combined NBSS from all four lake halves, predicted and empirically estimated average slopes matched very closely. Accordingly, our empirical results from aquatic ecosystems confirm the theoretically predicted relationship 
between TTE, PPMR and NBSS slope (Brown and Gillooly 2003, Reuman et al. 2008, Trebilco et al. 2013).

\section{Variables affecting the biomass-size distributions}

All 12 NBSS slopes covering bacteria to macrozoobenthos and the four slopes additionally including fish were significantly steeper than -1 . The significant deviations from -1 support the proposed relationship between the efficiency of energy transfer in food webs and the biomass-size distribution of the respective organisms (Brown et al. 2004, Trebilco et al. 2013). By considering the estimated TTE between $1 \%$ and $3.5 \%$ in the four lake halves, a size-related allometric metabolism exponent of 0.75 and a uniform PPMR of $10^{4}$, the expected NBSS slopes ranged between -1.25 and -1.11 (Appendix S1: Table S3). This range coincided with the range of the NBSS slopes measured in both lakes $(-1.14$ to -1.19$)$. However, the rank of measured TTE in the four lake halves did not correspond with the rank of the slopes in the four lake halves, and the CIs of the slopes overlapped between all four lake halves. This mismatch in rank order between NBSS slopes and empirically determined TTE suggests that, among other things, the precision of biomass, size, and production measurements was not high enough to generate statistically detectable differences between lake halves. However, a significant deviation from the expected NBSS slope of -1 has been documented in our empirical data, which confirms that the efficiency of energy transfer within food webs is reflected by the slopes of community-wide NBSS.

The second variable in the biomass-size distribution model is the PPMR, which has been fixed at $10^{4}$ for our calculations, following earlier suggestions (Brown and Gillooly 2003, Trebilco et al. 2013). However, less is known about the true PPMR in aquatic food webs. Estimating the average PPMR in the four lake halves would have required detailed stomach and gut content or stable isotope analyses for all individual consumers (Jennings et al. 2002), an effort we could not accomplish because of the large number of differing morphotypes and species characterized in the food webs of both lakes (Appendix S1: Table S1). However, the range of potential PPMRs as based on the size ranges of all broadly defined invertebrate predator-prey pairs such as ciliates-pelagic bacteria, ciliates-phytoplankton, rotifers-phytoplankton and crustaceans-phytoplankton includes $10^{4}$ (Appendix S1: Table S1).

Generally, the variation in the NBSS slope caused by variation in PPMR is relatively small. A hypothetical reduction or increase of the PPMR to $10^{3}$ or $10^{5}$ causes an NBSS slope of -1.08 and -0.95 , respectively, assuming a fixed TTE at $10 \%$. Therefore, with a TTE of $10 \%$, the global NBSS slope calculated across all four lake halves $(-1.17)$ would predict a PPMR as low as 240 (Appendix S1: Table S3), almost two orders of magnitude lower than the commonly assumed PPMR of $10^{4}$. Empirical estimates support that ciliates have a PPMR of about $10^{3}$, rotifers, nauplii, and copepodites have a PPMR of $10^{4}$, and PPMRs even greater than $10^{4}$ were found for cladocerans and meroplankton (Hansen et al. 1994). A PPMR of $10^{6}$ has been empirically determined for invertebrate and fish communities in the central North Sea (Jennings and Mackinson 2003). Consequently, an average
PPMR of $10^{4}$ across all feeding levels in our lakes seems reasonable and indicates that the low NBSS slopes have been caused primarily by the low TTE. Overall, a TTE in the range of $1-3 \%$, as observed in our lakes, would always result in NBSS slopes $<-1.1$ for every PPMR in the range of $10^{\circ}$ to $10^{4}$ (Trebilco et al. 2013).

The metabolic theory of ecology predicts that the metabolic rate (MR) of organisms scales with body mass $(M)$ as MR $\sim M^{0.75}$ (Brown et al. 2004). The true values of the allometric exponent and potential variations between organismal groups are under debate. For example, Lake Constance phyto- and zooplankton exhibited an allometric exponent of 0.85 (De Castro and Gaedke 2008), which would produce a slope of -1.1 at a TTE of $10 \%$, and a PPMR of $10^{4}$ (Appendix S1: Table S3). In turn, the empirically measured average NBSS slope of -1.17 across all four lake halves, combined with an allometric exponent of 0.85 and PPMR of $10^{4}$ would result in an average TTE of $5.2 \%$, which is outside the range of the estimated TTEs in Gollinsee and Schulzensee. Therefore, a metabolic exponent for all involved organisms substantially larger than 0.75 would have produced NBSS slopes substantially more negative than -1 , even without low TTEs. However, there are no systematic studies on the metabolic exponents of entire aquatic communities, and hence it is reasonable to apply 0.75 as the average metabolic coefficient (Brown et al. 2004).

\section{Community-wide size spectra}

We generated community-wide size spectra, which included organisms from bacteria to fish ranging over 53 $\log _{2}$ size classes. This range is equivalent to $17 \log _{10}$ size classes, and hence among the widest size ranges for aquatic size spectra reported in the scientific literature (Sheldon et al. 1972, Gaedke 1992, Sprules 2008, Yurista et al. 2014). Furthermore, we derived community size spectra by combining pelagic and benthic organisms, which are often considered to form spatially separate food webs (Vadeboncoeur et al. 2002). However, the benthic habitat was represented only by bacteria and macrozoobenthos in our study. The integration of benthic organisms into community size spectra is still in its infancy (Blanchard et al. 2009, 2017, Rogers et al. 2014). If benthic autotrophs such as epiphytes and epipelon have roughly the same size distribution as pelagic autotrophs, their biomasses would add to the biomasses per size group now covered by phytoplankton alone, and this may have an effect on the NBSS slope. However, a strong leverage effect from biomass variability of size groups in the middle of the distribution (such as phytoplankton or epiphyton) is highly unlikely, and hence the omission of benthic autotrophs from the NBSS should have only a marginal effect on the overall slope. Furthermore, we were unable to sample meiobenthic organisms properly. The few studies on freshwater meiobenthos size structure (Morin and Nadon 1991) suggest that most of the meiobenthos biomass is in the size classes larger than $2 \mathrm{~mm}$ (about $5 \mu \mathrm{g} \mathrm{C}$ per individual), which corresponds to a conspicuous trough in our sizefrequency distributions (Appendix S1: Fig. S1). Accordingly, it is likely that biomass-size data pairs of meiobenthos would fit into this trough without modifying the NBSS slope substantially. By including only macrozoobenthos and sediment 
bacteria, we could not calculate a separate NBSS for benthic habitats. However, future empirical comparisons of slopes and intercepts between pelagic and benthic size spectra for the same locality may reveal insights into potentially systematically differing TTE and PPMR between habitats (Blanchard et al. 2017).

Previous detailed analyses of the feeding interactions in the pelagic habitat of both lakes have shown that crustacean biomasses were reduced and ciliate biomasses increased as a consequence of a partial winter fish kill (Hilt et al. 2015, Lischke et al. 2016). The resulting strong predation pressure by ciliates likely reduced the biomass of small phytoplankton and pelagic bacteria and benefitted large phytoplankton species (Lischke et al. 2016). Furthermore, quantitative analyses of C fluxes within Gollinsee and Schulzensee have indicated that the production of sediment bacteria was only partly converted into consumer production, resulting in high biomasses of benthic bacteria (Lischke et al. 2017). The average residuals for each organismal group from the global NBSS slope calculated in this study reflected these deviations, as we found strongly negative residuals for pelagic bacteria and crustaceans, and strongly positive residuals for sediment bacteria, ciliates, and the larger phytoplankton morphotypes. Surprisingly, the global NBSS slope, which reflects the TTE of the entire food web, is relatively insensitive to these substantial deviations of organismal biomass from the biomass predicted according to the TTE-corrected biomass-size distributions (Sprules 2008). Overall, such an invariance of community NBSS slopes, despite biomass variations of single organismal groups in the dimension of one or two magnitudes, suggests that a strong depletion of biomass in single prey groups by predators may be balanced by compensatory increases in the biomass of less-utilized prey groups. From that perspective, the community NBSS slope poorly reflects the biomass pools in food webs, which result from the varying intensity of several trophic interactions.

However, the NBSS slope is sensitive enough to reflect the global energy flow and overall efficiency of trophic transfer within the community. NBSS slopes substantially steeper than -1 may then suggest that the community TTE is low, which may indicate that single predator-prey interactions or trophic levels in sub-webs may have remained undetected (Lischke et al. 2017). Alternatively, a low TTE may indicate the depletion of certain trophic levels by natural or anthropogenic effects, which would cause an interruption in the continuous energy flow from smaller to larger organisms. In turn, NBSS slopes shallower than -1 would indicate TTEs larger than $10 \%$, suggesting that some trophic levels may be subsidized by energy produced outside of the system, for example by terrestrial organic carbon entering aquatic ecosystems, or by highly mobile predators, whose activity ranges are larger than the spatial scale at which the community NBSS has been accumulated (Trebilco et al. 2013). Accordingly, the NBSS slopes can provide information on food web structure and energetic pathways, and can improve the accuracy of TTE estimates.

Our approach is based on the combination of empirically derived correlations between the density and size of organisms with the concept of trophic levels in communities which are linked by predation (Trebilco et al. 2013). Therefore, it is an expansion of the energy equivalence rule (Damuth 1981,
Nee et al. 1991) and the metabolic-scaling theory (Brown et al. 2004). There are, admittedly, alternative concepts to model community size distributions which do not explicitly consider TTE, but which predict similar NBSS slopes to those calculated in this study. For example, Law et al. (2009) used a stochastic individual-based model for the dynamics of size spectra, based on birth, growth, and death of individuals, resulting in a linear size spectrum with a slope of approximately -1 . In another model considering marine zooplankton, the biomass flux from smaller to larger sizes resulted in similar slopes to those calculated here, and emerged from a balance among individual birth, growth, natural death, and predation (Zhou and Huntley 1997). In even more complex community models, many species or groups of animals with similar life histories were linked through feeding interactions, and expended energy on metabolism, growth and reproduction (Andersen and Beyer 2006, Hartvig et al. 2011). In a comprehensive analysis of these kinds of models, trophic interaction strengths were found to depend only on predator and prey sizes, reaching maximum values at certain PPMR ratios (Rossberg 2012). However, when a high productivity enables all consumers to feed ad libitum, the slope of the resulting NBSS again depends on the energy transfer efficiency from smaller to larger species (Rossberg 2012). Therefore, the different approaches to model community size distributions converge in surprisingly similar patterns (Rossberg 2012, Sprules and Barth 2016), because the transfer efficiency between aggregated trophic levels is equivalent to the average individual metabolic net efficiency of the organisms at these trophic levels. Accordingly, the size-related predator-prey interactions and the efficiency of individuals to convert food into biomass are the primary determinants of the empirically documented declines of abundance with increasing organism size in multi-trophic food webs.

In conclusion, community-level indicators such as the NBSS, which are simple to estimate and have a mechanistic ecological basis, may provide insights into the structural and functional properties of ecosystems, which are often difficult to assess directly (Jennings et al. 2008). For example, declining ecosystem stability can be predicted from disrupted slopes of size spectra caused by overfishing or warming, because of the inefficient transfer of energy through the food web and a shift towards faster growth rates and stronger abundance fluctuations of the overall community (YvonDurocher et al. 2011, Blanchard et al. 2012). Therefore, the comparison between theoretically predicted and empirically derived community size structures may inform us of the consequences of global warming, species invasions, habitat alterations, and human exploitation on ecosystems processes and services, feeding interactions, and biogeochemical cycles (Blanchard et al. 2017, Brose et al. 2017).

\section{ACKNOWLEDGMENTS}

We thank Kate Laskowski and Christian Guill for help with the statistical analyses, Jochen Diekmann who analyzed part of the raw data, and two anonymous reviewers whose comments helped improving the text. The work was funded by grants from the Wissenschaftsgemeinschaft Gottfried Wilhelm Leibniz (WGL) to TM, BL, KA, SB, KS, UG and SH (project TERRALAC) and the Deutsche Forschungsgemeinschaft (DFG) to TM and SB (grant no. Me 1686/7-1). 


\section{Literature Cited}

Andersen, K. H., and J. E. Beyer. 2006. Asymptotic size determines species abundance in the marine size spectrum. American Naturalist 168:54-61.

Best, E. P. H. 1982. The aquatic macrophytes of Lake Vechten - species composition, spatial distribution and production. Hydrobiologia 95:65-77.

Blanchard, J. L., R. F. Heneghan, J. D. Everett, R. Trebilco, and A. J. Richardson. 2017. From bacteria to whales: using functional size spectra to model marine ecosystems. Trends in Ecology \& Evolution 32:174-186.

Blanchard, J. L., S. Jennings, R. Holmes, J. Harle, G. Merino, J. I. Allen, J. Holt, N. K. Dulvy, and M. Barange. 2012. Potential consequences of climate change for primary production and fish production in large marine ecosystems. Philosophical Transactions of the Royal Society B 367:2979-2989.

Blanchard, J. L., S. Jennings, R. Law, M. D. Castle, P. McCloghrie, M. J. Rochet, and E. Benoit. 2009. How does abundance scale with body size in coupled size-structured food webs? Journal of Animal Ecology 78:270-280.

Brose, U., et al. 2017. Predicting the consequences of species loss using size-structured biodiversity approaches. Biological Reviews 92:684-697.

Brothers, S. M., S. Hilt, S. Meyer, and J. Köhler. 2013. Plant community structure determines primary productivity in shallow, eutrophic lakes. Freshwater Biology 58:2264-2276.

Brothers, S., Y. Vadeboncoeur, and P. Sibley. 2016. Benthic algae compensate for phytoplankton losses in large aquatic ecosystems. Global Change Biology 22:3865-3873.

Brown, J. H., and J. F. Gillooly. 2003. Ecological food webs: highquality data facilitate theoretical unification. Proceedings of the National Academy of Sciences USA 100:1467-1468.

Brown, J. H., J. F. Gillooly, A. P. Allen, V. M. Savage, and G. B. West. 2004. Toward a metabolic theory of ecology. Ecology 85:1771-1789.

Buesing, N., and M. O. Gessner. 2003. Incorporation of radiolabeled leucine into protein to estimate bacterial production in plant litter, sediment, epiphytic biofilms, and water samples. Microbial Ecology 45:291-301.

Cyr, H. 1997. Cladoceran- and copepod-dominated zooplankton communities graze at similar rates in low-productivity lakes. Canadian Journal of Fisheries and Aquatic Sciences 55: $414-422$.

Damuth, J. 1981. Population-density and body size in mammals. Nature 290:699-700.

De Castro, F., and U. Gaedke. 2008. The metabolism of lake plankton does not support the metabolic theory of ecology. Oikos 117:1218-1226.

Gaedke, U. 1992. The size distribution of plankton biomass in a large lake and its seasonal variability. Limnology and Oceanography 37:1202-1220.

Gaedke, U., D. Straile, and C. Pahl-Wostl. 1996. Trophic structure and carbon flow dynamics in the pelagic community of a large lake. Pages 60-71 in G. A. Polis and K. O. Winemiller, editors. Food webs. Integration of patterns and dynamics. Chapman \& Hall, New York, New York, USA.

Hansen, B., P. K. Bjornsen, and P. J. Hansen. 1994. The size ratio between planktonic predators and their prey. Limnology and Oceanography 39:395-403.

Hartvig, M., K. H. Andersen, and J. E. Beyer. 2011. Food web framework for size-structured populations. Journal of Theoretical Biology 272:113-122.

Hilt, S., T. Wanke, K. Scharnweber, M. Brauns, J. Syväranta, S. Brothers, U. Gaedke, J. Köhler, B. Lischke, and T. Mehner. 2015 Contrasting response of two shallow eutrophic cold temperate lakes to a partial winterkill of fish. Hydrobiologia 749:31-42.

Jennings, S., and S. Mackinson. 2003. Abundance-body mass relationships in size-structured food webs. Ecology Letters 6: 971-974.
Jennings, S., F. Melin, J. L. Blanchard, R. M. Forster, N. K. Dulvy, and R. W. Wilson. 2008. Global-scale predictions of community and ecosystem properties from simple ecological theory. Proceedings of the Royal Society B-Biological Sciences 275:1375-1383.

Jennings, S., K. J. Warr, and S. Mackinson. 2002. Use of size-based production and stable isotope analyses to predict trophic transfer efficiencies and predator-prey body mass ratios in food webs. Marine Ecology Progress Series 240:11-20.

Kerr, S. R., and L. M. Dickie. 2001. The biomass spectrum. Columbia University Press, New York, New York, USA.

Law, R., M. J. Plank, A. James, and J. L. Blanchard. 2009. Sizespectra dynamics from stochastic predation and growth of individuals. Ecology 90:802-811.

Lindeman, R. L. 1942. The trophic-dynamic aspect of ecology. Ecology 23:399-417.

Lischke, B., T. Mehner, S. Hilt, K. Attermeyer, M. Brauns, S. Brothers, H. P. Grossart, J. Köhler, K. Scharnweber, and U. Gaedke. 2017. Benthic carbon is inefficiently transferred in the food webs of two eutrophic shallow lakes. Freshwater Biology 62:1693-1706.

Lischke, B., G. Weithoff, S. A. Wickham, K. Attermeyer, H. P. Grossart, K. Scharnweber, S. Hilt, and U. Gaedke. 2016. Large biomass of small feeders: ciliates may dominate herbivory in eutrophic lakes. Journal of Plankton Research 38:2-15.

Marquet, P. A. 2000. Ecology - invariants, scaling laws, and ecological complexity. Science 289:1487-1488.

Mehner, T., et al. 2016. Weak response of animal allochthony and production to enhanced supply of terrestrial leaf litter in nutrientrich lakes. Ecosystems 19:311-325.

Morin, A., and D. Nadon. 1991. Size distribution of epilithic lotic invertebrates and implications for community metabolism. Journal of the North American Benthological Society 10:300-308.

Nee, S., A. F. Read, J. J. D. Greenwood, and P. H. Harvey. 1991. The relationship between abundance and body size in British birds. Nature 351:312-313.

Pauly, D., and V. Christensen. 1995. Primary production required to sustain global fisheries. Nature 374:255-257.

Plante, C., and J. A. Downing. 1989. Production of freshwater invertebrate populations in lakes. Canadian Journal of Fisheries and Aquatic Sciences 46:1489-1498.

R Core Team. 2016. R: a language and environment for statistical computing. R Foundation for Statistical Computing, Vienna, Austria.

Reuman, D. C., C. Mulder, D. Raffaelli, and J. E. Cohen. 2008. Three allometric relations of population density to body mass: theoretical integration and empirical tests in 149 food webs. Ecology Letters 11:1216-1228.

Rogers, A., J. L. Blanchard, and P. J. Mumby. 2014. Vulnerability of coral reef fisheries to a loss of structural complexity. Current Biology 24:1000-1005.

Rossberg, A. G. 2012. A complete analytic theory for structure and dynamics of populations and communities spanning wide ranges in body size. Advances in Ecological Research, Vol 46: Global Change in Multispecies Systems, Pt 1 46:427-521.

Scharnweber, K., J. Syväranta, S. Hilt, M. Brauns, M. J. Vanni, S. M. Brothers, J. Köhler, J. Knezevic-Jaric, and T. Mehner. 2014. Whole-lake experiments reveal the fate of terrestrial particulate organic carbon in benthic food webs of shallow lakes. Ecology 95:1496-1505.

Sheldon, R. W., W. H. Sutcliff, and A. Prakash. 1972. Size distribution of particles in ocean. Limnology and Oceanography 17:327-340.

Shuter, B. J., and K. K. Ing. 1997. Factors affecting the production of zooplankton in lakes. Canadian Journal of Fisheries and Aquatic Sciences 54:359-377.

Simon, M., and F. Azam. 1989. Protein content and protein synthesis rates of planktonic marine bacteria. Marine Ecology Progress Series 51:201-213.

Sprules, W. G. 2008. Ecological change in Great Lakes communities - a matter of perspective. Canadian Journal of Fisheries and Aquatic Sciences 65:1-9. 
Sprules, W. G., and L. E. Barth. 2016. Surfing the biomass size spectrum: some remarks on history, theory, and application. Canadian Journal of Fisheries and Aquatic Sciences 73:477-495.

Stockwell, J. D., and O. E. Johannson. 1997. Temperature-dependent allometric models to estimate zooplankton production in temperate freshwater lakes. Canadian Journal of Fisheries and Aquatic Sciences 54:2350-2360.

Syväranta, J., K. Scharnweber, M. Brauns, S. Hilt, and T. Mehner. 2016. Assessing the utility of hydrogen, carbon and nitrogen stable isotopes in estimating consumer allochthony in two shallow eutrophic lakes. PLoS ONE 11:ARTN e0155562.

Trebilco, R., J. K. Baum, A. K. Salomon, and N. K. Dulvy. 2013. Ecosystem ecology: size-based constraints on the pyramids of life. Trends in Ecology \& Evolution 28:423-431.

Vadeboncoeur, Y., M. J. Vander Zanden, and D. M. Lodge. 2002. Putting the lake back together: reintegrating benthic pathways into lake food web models. BioScience 52:44-54.
White, E. P., B. J. Enquist, and J. L. Green. 2008. On estimating the exponent of power-law frequency distributions. Ecology 89:905-912.

White, E. P., S. K. M. Ernest, A. J. Kerkhoff, and B. J. Enquist. 2007. Relationships between body size and abundance in ecology. Trends in Ecology and Evolution 22:323-330.

Yurista, P. M., D. L. Yule, M. Balge, J. D. VanAlstine, J. A. Thompson, A. E. Gamble, T. R. Hrabik, J. R. Kelly, J. D. Stockwell, and M. R. Vinson. 2014. A new look at the Lake Superior biomass size spectrum. Canadian Journal of Fisheries and Aquatic Sciences 71:1324-1333.

Yvon-Durocher, G., J. M. Montoya, M. Trimmer, and G. Woodward. 2011. Warming alters the size spectrum and shifts the distribution of biomass in freshwater ecosystems. Global Change Biology 17:1681-1694.

Zhou, M., and M. E. Huntley. 1997. Population dynamics theory of plankton based on biomass spectra. Marine Ecology Progress Series 159:61-73.

\section{SUPPORTING INFORMATION}

Additional supporting information may be found in the online version of this article at http://onlinelibrary.wiley.com/doi/10.1002/ecy. 2347/suppinfo 